\title{
Berimbau: instâncias de decisão compartilhada em uma composição colaborativa
}

\section{Berimbau: instances of shared decision- making in collaborative composition}

Alexandre Espinheira ${ }^{1}$ Universidade Federal da Bahia alespinheira@gmail.com

Luciane Cardassiz

Universidade Federal da Bahia luciane.cardassi@gmail.com 


\section{Resumo}

O presente artigo apresenta uma reflexão sobre a composição colaborativa da obra Berimbau para piano, voz e sons eletroacústicos. Os objetivos intentados foram: a) oferecer um panorama do estado da arte da pesquisa em colaboração artística (JOHN-STEINER, 2000; BARRET, 2014) e da criatividade distribuída (CLARKE; DOFFMAN, 2017); b) descrever brevemente as teorias da composição desenvolvidas por Laske (1991) e Reynolds (2002), iluminadas por Rios Filho (2010); e, a partir delas, c) propor uma reflexão sobre instâncias de decisão compartilhada entre colaboradores com o objetivo de compor uma obra musical. Para tanto, utilizamos episódios do processo colaborativo da obra Berimbau para exemplificar as diversas fases e instâncias de decisão propostas no esquema. Acreditamos que o presente artigo possa ser somado às iniciativas de reflexão acerca da colaboração artística e oferecer alternativas para a compreensão e estudo de como os processos colaborativos podem ser desenvolvidos.

Palavras-chave: Composição colaborativa, instâncias de decisão, colaboração compositor-performer.

\section{Abstract}

This article offers reflections about the collaborative process in creation of Berimbau for piano, voice and electroacoustic sounds. The intended objectives were: a) to offer a wide panorama of perspectives on the state of the art in research on artistic collaboration (JOHN-STEINER, 2000; BARRET, 2014) and of distributed creativity (CLARKE; DOFFMAN, 2017); b) to briefly describe the composition theories developed by Laske (1991) and Reynolds (2002), illuminated by Rios Filho (2010); and c) from those, reflect upon instances of shared decision-making between collaborators in the composition process of the work Berimbau. In order to do so, we refer to specific episodes from our collaboration process to exemplify the various phases and instances of decisions. We believe that the approach presented here complements other research in this area, contributing to deeper understanding of artistic collaboration.

Keywords: Collaborative composition, shared decision-making, composer-performer collaboration.

\footnotetext{
$1 \quad$ Mestre e Doutor em Música pela Universidade Federal da Bahia, onde leciona desde 2017. Compôs pouco mais de 70 obras tocadas em diversas cidades brasileiras e de outros países. Sua pesquisa atual envolve teoria pós-tonal e poética a partir do background cultural de instrumentos tradicionais. https://orcid.org/0000-0001-7736-0491
}

2 Professora Visitante do PPGMUS-UFBA. Doutora em Performance da Música Contemporânea pela Universidade da Califórnia, SanDiego (UCSD), Mestre em Música pela UFRGS e Bacharel em Música pela USP. É pesquisadora na área de Performance Musical e Colaboração com Compositores. 


\section{Introdução}

Este texto parte do pressuposto de que criatividade, particularmente em processos artísticos colaborativos, não é algo exclusivo de um indivíduo, mas acontece de maneira distribuída entre os participantes do processo criativo (CLARKE; DOFFMAN, 2017). Se o conceito de criatividade distribuída produziu o alicerce inicial para nossa pesquisa, foram as reflexões sobre colaboração entre compositores e performers - mais notadamente a bibliografia recente dos pesquisadores Hayden e Windsor (2007), Domenici (2013), John-Steiner (2000) e Barrett (2014), além de Cardassi e Bertissolo $(2019,2020)$ -, que proporcionaram as bases teóricas para o desenvolvimento de nossa colaboração artística e para a elaboração deste artigo.

Acreditamos que processos colaborativos tendem a acontecer entre profissionais que demonstram interesses em comum e que, muitas vezes, amizades precedem parcerias profissionais (DOMENICl, 2013). Adotamos a nomenclatura proposta por Hayden e Windsor (2007), segundo a qual a colaboração acontece quando "o desenvolvimento da música é alcançado através de um processo coletivo de tomada de decisão. Não há autor único nem hierarquia de papéis" (HAYDEN; WINDSOR, 2007, p.33). Em colaborações dessa natureza - horizontal, não hierárquica -, os indivíduos têm o potencial de aprofundar a experiência e o conhecimento sobre seu próprio métier, corroborando o que John-Steiner (2000) denomina "paradoxo da colaboração":

Existe um profundo paradoxo na colaboração produtiva. As capacidades de cada indivíduo são aprofundadas enquanto descobrem os benefícios da reciprocidade... para isto é preciso tempo e esforço. Envolve a criação de uma linguagem compartilhada, os prazeres e riscos de um diálogo honesto e a busca por um terreno comum. Em atividades colaborativas nós aprendemos uns com os outros, nós nos envolvemos em apropriação mútua, nós nos vemos através dos olhos dos outros e, com seu apoio, podemos explorar novas partes de nós mesmos. Quando nos juntamos a outros, aceitamos seu gesto de confiança e, através de interdependência, alcançamos competência e conexão. (JOHN-STEINER, 2000, p.204).

Com a expectativa de aprofundar a experiência e o conhecimento sobre processos colaborativos, e abraçando o paradoxo da reciprocidade, os autores deste texto se propuseram a desenvolver uma atividade de criação colaborativa entre julho de 2018 e abril de 2019, a qual levou à produção da obra Berimbau, para piano (+ voz) e sons eletroacústicos.

Vale ressaltar que, tanto em nosso trabalho artístico quanto na escrita deste texto, partimos do princípio de que colaboração entre compositor e performer é uma possibilidade criativa e de aprendizado, mas em nenhum momento sugerimos que esse seja o único caminho. Ao contrário, são muitos os caminhos, tanto na criação individual realizada por compositores e performers quanto na maneira e no grau de envolvimento deles em projetos colaborativos.

Nosso processo colaborativo se desenvolveu de maneira orgânica, em encontros regulares, onde tratamos de assuntos relativos à música que estávamos criando e sua 
performabilidade, mas também sobre assuntos aparentemente periféricos, mas que, acreditamos, tenham sido essenciais para o estabelecimento de uma relação de parceria e de confiança entre nós. Não tivemos a intenção de questionar neste projeto a noção de autoria da composição. O que buscamos foi uma parceria na tomada de decisões no decorrer do processo colaborativo, partindo do princípio de que, nesse processo, compositor e performer aprofundam o conhecimento em sua área de expertise.

Diferentemente de uma interação em que o performer participa apenas como um consultor técnico, procuramos alcançar aqui um nível de interação verdadeiramente colaborativo entre compositor e performer, seguindo o conceito de Hayden e Windsor (2007). Além disso, a análise de nosso processo colaborativo só foi possível por meio de estratégias de registro que tomamos emprestado da crítica genética (SALLES, 2000, 2014; CHAVES, 2012) e de dados etnográficos (FORTIN, 2009; RIOS FILHO, 2015). Por sua vez, a análise do processo composicional em si foi corroborada por teorias recentes sobre processos de composição.

Neste artigo, procuraremos discorrer sobre nossa trajetória durante o processo colaborativo que resultou na obra Berimbau, chamando atenção para os efeitos transformadores de alguns momentos - que denominaremos episódios - e que constituíram situações e estágios desse processo que reforçam o caráter distribuído da criatividade. Esses episódios explicitam decisões compartilhadas que direcionaram a criação. São exemplos práticos de interseções importantes, onde os trabalhos do compositor e da performer, se estivessem sendo desenvolvidos isoladamente, teriam certamente seguido caminhos muito diversos.

Acreditamos que o estudo desses episódios ilumina a natureza distributiva e recíproca de nossa colaboração. Foi a partir desse nível microscópico, enquanto fazíamos uma lista e dávamos nome aos episódios, que começamos a pensar em uma possível organização deles em nível macroscópico, inspirados pelos modelos de teorias da composição de Laske (1991) e Reynolds (2002). Chegamos, assim, a um modelo de organização daquilo que chamamos de instâncias de decisão compartilhada, o qual é elaborado neste texto.

Portanto, o objetivo principal deste artigo é apresentar um modelo de organização do processo colaborativo em instâncias de decisão compartilhada. Para exemplificarmos essas instâncias, usamos nosso processo colaborativo na produção da obra Berimbau, para piano (+ voz) e sons eletroacústicos. Os recursos advindos da crítica genética, da etnografia e da autoetnografia nos auxiliaram na documentação e registro dos rastros de nossa colaboração, o que foi fundamental para que a reflexão que elaboramos aqui fosse possível. Buscamos também oferecer um breve panorama do estado da arte da pesquisa em colaboração artística hoje, além de dialogar com algumas teorias de composição para embasamento teórico de nosso modelo. Esperamos que esta reflexão sobre episódios de um processo colaborativo e a organização do processo em instâncias de decisão compartilhada sejam úteis a colegas acadêmicos, colaboradores, artistas de nosso século. 


\section{Criatividade distribuída e registro do processo}

"Apoiado em desenvolvimentos conceituais em musicologia, psicologia, antropologia, sociologia, computação e neurociência, observa-se um crescente reconhecimento da extensão e do caráter distribuído dos processos criativos em música" (CLARKE; DOFFMAN, 2017, p.2). Essa ideia, acreditamos, não deveria soar nova. Afinal, a maioria das músicas, independentemente de gênero ou local, normalmente valoriza essa distribuição. Exemplo disso é a formação de grupos para criação e performance da música popular - em que indivíduos se unem a partir de características individuais, e o som resultante do grupo incorpora e valoriza essas vozes particulares e únicas. A criatividade de um grupo de rock, por exemplo, reside na combinação de suas individualidades. Sua criatividade, portanto, está evidentemente distribuída entre os participantes.

No que se refere à música de concerto dos últimos 200 anos, a história tem sido outra. O paradigma que culminou com o Modernismo do século XX colocou a figura do compositor ou compositora em posição de detentor único e exclusivo da criatividade em uma composição musical. Naquele modelo, especialmente a partir dos compositores da Segunda Escola de Viena, o objetivo do processo criativo era chegar a uma partitura, independentemente de ela ser tocada ou não. Esse paradigma parece anacrônico e obsoleto para nós, músicos e pesquisadores da música de concerto do século XXI.

De fato, autores como Nicholas Cook (2006) vêm discutindo a necessidade de se abordar todo o processo criativo como objeto de estudo e como parte da criação artística, e não apenas a composição, individual, consagrada em um produto final - a partitura. Afinal, a música resulta da interação de vários indivíduos, desde sua ideia inicial, passando por muitos estágios de criação, até a realização de uma performance e, finalmente, chegando à fruição pelos ouvintes (participantes desse processo - seja de forma ativa, seja de forma passiva). Portanto, não é possível mais aceitar que a criatividade exista exclusivamente na mente de um indivíduo apenas.

Além disso, acreditamos que a música de concerto contemporânea, por existir em proximidade (senão dentro) da academia, oferece o substrato perfeito para a reflexão sobre processos criativos e criatividade distribuída. Por certo, os indivíduos criadores e acadêmicos coexistem nas universidades e nos centros de pesquisa e podem atuar tanto como participantes quanto como pesquisadores de suas colaborações (CLARKE; DOFFMAN, 2017).

Acreditamos que o estudo sobre criatividade distribuída possa contribuir para uma grande transformação, que julgamos necessária, em que processos colaborativos, especialmente entre compositores e performers, sejam estudados de maneira mais aprofundada. Para tanto, é imprescindível o registro detalhado dos processos. É nesse ponto que temos nos apoiado em elementos provenientes da crítica genética e de dados etnográficos, especialmente através dos autores Salles (2000), Fortin (2009), Chaves (2012) e Rios Filho (2015). Para Salles, um estudo em crítica genética pode ser descrito como "uma investigação que indaga a obra de arte a partir de sua fabricação, a partir de sua gênese" (SALLES, 2000, p.24). 
Nessa investigação, faz-se necessário o estudo de documentos do processo, o que a autora chama de rastros. Segundo Fortin, os dados etnográficos - ou seja, a documentação do processo - compreendem, além de notas descritivas e analíticas, o registro de notas metodológicas. As sensações e emoções acerca do processo também devem ser reconhecidas como fonte de informação. No nosso caso, essa documentação compreende desde esboços, anotações em diários, gravações de experimentações ao instrumento até trocas de mensagens de e-mail, registro de conversas em Skype ${ }^{3}$, troca de mensagens de voz no WhatsApp ${ }^{4}$, além, é claro, de versões da partitura ${ }^{5}$ e de gravações. Importa salientar que não podemos nos restringir aos documentos físicos e digitais desse processo, pois, tratando-se de composição musical, devemos sempre considerar a "restituição da materialidade do som" e a "reconstrução do passar do tempo na música" (CHAVES, 2012, p.237). Segundo o autor,

Ao contrário de outras áreas de formulação e aplicação da crítica genética, em música o objeto sonoro deve ser ressignificado em som, a cada passo e nas suas completudes e incompletudes, evitando um enfoque exclusivamente teórico que trairia a própria natureza do objeto investigado. (CHAVES, 2012, p.245).

A partir dos registros do processo colaborativo - sem nunca desconsiderar, é claro, a temporalidade da música -, podemos observar um número enorme de momentos - alguns aparentemente insignificantes, outros essenciais - que levaram ao resultado criativo em questão e que reforçam o caráter fluido do processo colaborativo (CLARKE; DOFFMAN, 2017, p.14). Ao refletir sobre processos colaborativos, que são intrinsecamente fluidos, emaranhados e difíceis de singularizar, encontramos amparo em teorias estabelecidas sobre a organização do fazer composicional.

\section{Teorias da composição}

Parece-nos evidente que o processo colaborativo pode estar presente, se não em todas, em muitas das decisões no processo de composição. Alguns autores propuseram teorizações sobre os processos envolvidos no fazer composicional que iluminam e descrevem algumas de suas etapas. Dentre esses, estão Reynolds e Laske. Reynolds (2002) propõe, permeado por um grande emaranhado de conceitos, um esquema geral simples em que, no nível mais elevado, está a forma e, no mais básico, o material. No meio, está o método, que são os processos pelos quais o compositor transforma o menor no maior, assegurando que os dois primeiros não se tornem estranhos no processo. Rey-

\footnotetext{
3 O Skype é um aplicativo de comunicação multiplataforma, do tipo voz sobre IP, com licença freeware. O aplicativo permite a comunicação por voz e vídeo, tanto individual quanto em grupo.

$4 \quad$ O WhatsApp é um aplicativo de comunicação por mensagens instantâneas que permite, além da troca de mensagens de texto, troca de mensagens de áudio e chamadas por áudio e vídeo.

5 Consideramos aqui que a partitura, apesar de não ser o objetivo final dessa colaboração, é parte importante desse processo, tanto para traçar caminhos através dos rastros deixados por suas versões quanto como um dos possíveis registros da obra, apesar de limitado e parcial, mas possível dentro das tradições em que está inserida.
} 
nolds também deixa claro que se pode partir de quase qualquer ponto desse "caminho fechado e interdependente entre forma, material e método" (REYNOLDS, 2002, p.4).

Já Laske propõe um ciclo de vida da composição que "compreende todos os processos (mentais e materiais, imaginativos bem como factuais) que ocorrem durante o ato de fazer arte" (LASKE, 1991, p.244.). Segundo Rios Filho (2010, p.41), ao comentar Laske, “qualquer composição artística - apesar de o autor dar ênfase à musical - compreende um nível da ideia, que gera um plano, e segue para três modelos complementares, passando por diversos estágios até o resultado final, o próprio objeto/obra". E complementa:

\begin{abstract}
Esses estágios são, como observado, o nível analítico, o nível de síntese, o de especificação e o de implementação da obra de arte. É no primeiro deles que o material é coletado e seus dados são avaliados e entendidos, em sua versão "crua". $\mathrm{Na}$ etapa da síntese, essas coleções estáticas de material são transformadas em limites e restrições no sentido da criação de um design compositivo funcional. No nível da especificação, "essas restrições são então usadas [...] para bosquejar as funções e as relações funcionais entre componentes da obra de arte" (LASKE, 1991, p.245). Finalmente, no nível da implementação, essas relações funcionais são aplicadas por meio de operações e materializadas em termos de recursos específicos. (RIOS FILHO, 2010, p.41).
\end{abstract}

Em um esforço para interpretar e encontrar interseções entre os esquemas desses dois teóricos - e reconhecendo que o de Reynolds possui menos elementos que o de Laske -, Rios Filho (2010, p.44) propõe "trançar um no outro", onde "um extrato do esquema de Laske é interpretado como um detalhamento do esquema tripartido de Reynolds":

Assim, o nível analítico, o de especificação e o nível da obra (da parte de Laske) estão inteiramente relacionados, respectivamente, ao material, ao método e à forma (da parte de Reynolds). Por sua vez, os níveis de síntese e implementação (Laske) são o açambarcamento de etapas mais ambíguas, das interseções entre, no caso do primeiro, o material e o método, e do segundo, entre o método e a forma. (RIOS FILHO, 2010, p.44).

Os processos criativos, especificamente na música de concerto dos últimos 200 anos, vêm sendo analisados pelo prisma do paradigma da criação individual. Dessa forma, cada compositor desenvolve seu próprio processo criativo, o qual, portanto, varia muito entre compositores e até mesmo entre obras de um mesmo compositor. Apesar de estarmos neste texto tratando de criações colaborativas, acreditamos que as reflexões de Laske e Reynolds, iluminadas por Rios Filho, podem nos orientar na reflexão sobre nossos processos criativos - nesse caso, não individuais, mas colaborativos.

\title{
4. Instâncias de decisão compartilhada
}

A partir de nossas reflexões acerca do fazer composicional, e tentando criar um esquema que transite do paradigma da criação individual para o da criação colaborativa, propomos pensar em instâncias de decisão compartilhada que podem ser partilhadas em um processo criativo. Imaginamos assim uma estrutura que contempla as etapas 
expostas por Reynolds e Laske, mas se amplia com a inclusão de certas instâncias que, talvez, só façam sentido através do prisma da composição colaborativa. Dessa forma, propomos dividir o processo de colaboração em basicamente duas etapas: 1) planejamento e 2) implementação - cujas subdivisões serão detalhadas neste texto.

Na primeira fase - a de planejamento -, as primeiras decisões compartilhadas começam a dar forma à obra e ao processo de colaboração. Nessa etapa, podemos identificar três instâncias de decisão. A primeira delas seria a estética. Parece-nos que as decisões sobre esse tema não são necessariamente tomadas de maneira consciente nem que, muitas vezes, haja uma conversa sobre isso. Essa decisão acontece, quase que inconscientemente, no momento em que é feito o convite para a colaboração, pois acreditamos que afinidades estéticas fazem parte dos critérios iniciais para que se convide alguém para uma colaboração performer/compositor. Essa instância não é descrita por nenhum dos teóricos da composição citados. Acreditamos que isso se deva ao fato de ela não fazer sentido fora do paradigma da composição colaborativa.

Outra instância de decisão da fase de planejamento seria a das ideias iniciais: as que são as sementes da obra e que, segundo Laske, vão se desdobrar, por meio das etapas analítica, de síntese e de implementação, até o resultado final. Chamamos essa fase de impetus, como nomeia Reynolds. O impetus, para Reynolds (2002, p.8), é a "essência radiante e concentrada da qual o todo emerge". O plano da obra, que chamamos de design formativo, e os primeiros materiais são duas das subdivisões dessa instância de decisão.

Uma terceira instância de decisão nessa fase seria a logística - em que se definem elementos de natureza prática que possam viabilizar (ou inviabilizar) as possíveis performances da música. Por exemplo, a quantidade de canais utilizados em um tape ou determinadas preparações no piano podem inviabilizar a execução em determinados locais. São aspectos técnicos que não estão relacionados com a técnica instrumental. Optamos, assim, por utilizar uma nomenclatura especial para essas questões, evitando que se confundam com questões técnicas instrumentais.

Na segunda fase - implementação -, constam instâncias de decisão compartilhada que vão guiar o andamento do projeto em execução, visando à forma final. É importante ressaltar que, dentro do processo colaborativo, os encontros frequentes, mesmo que não presenciais, para trocas de informação e discussão sobre o trabalho em andamento, são fundamentais. Eles têm um grande potencial transformador, como poderá ser observado adiante ao discorrermos sobre alguns episódios em Berimbau.

A fase de implementação também está subdividida em três instâncias de decisão compartilhada. A primeira, de caráter técnico, envolve decisões sobre a execução instrumental dos materiais no processo composicional e a utilização de recursos tecnológicos. Como veremos em alguns episódios a seguir, é fundamental que o performer assuma uma postura ativa, aberta e participativa nessa fase, pois é aí que os materiais serão lapidados. Se sua participação for pequena, ou nenhuma, as decisões sobre os materiais iniciais e sobre sua performabilidade - considerando dificuldades técnicas, conforto ao executar e inclusive expectativas - serão tomadas exclusivamente pelo compositor, o qual continuará a compor sobre esses materiais iniciais. Chegando ao final de uma 
obra, a revisão desses elementos iniciais e de sua performabilidade se tornará uma tarefa praticamente impossível, pois, em alguns casos, considerando que materiais são constantemente reutilizados dentro de uma peça, seria necessário reescrevê-la quase que completamente.

A segunda instância de decisão nessa fase seria a que estabelece os processos através dos quais o compositor liga o menor (material) ao maior (forma), assegurando que os dois não se tornem estranhos (REYNOLDS, 2002). Pode parecer natural que esses processos mais intimamente ligados à transformação e à adequação dos materiais à forma que se desenha estejam mais conectados ao métier do compositor, afinal historicamente sempre esteve. Nessa colaboração em específico, a performer participou pouco das decisões nessa instância, talvez porque o compositor tenha sempre se antecipado nessas etapas e trazido as seções já compostas. Acreditamos, contudo, que as decisões acerca dos processos podem ter maior participação dos performers em um ambiente de criação colaborativa.

A terceira instância de decisão na fase de implementação talvez seja a mais importante. Segundo a Estética da Formatividade de Pareyson, a obra de arte é "um tal fazer que, enquanto faz, inventa o por fazer e o modo de fazer" (PAREYSON, 1997, p.27). É exatamente nessa instância de decisão - a das avaliações periódicas - que acabamos por conceber executando, projetar fazendo, encontrar a regra operando. De fato, é através dessas avaliações periódicas que comparamos continuamente o planejamento com a implementação em andamento, com as expectativas pessoais dos agentes envolvidos e aquelas criadas pela própria obra.

Em um paradigma de criação individual, essa etapa pode até mesmo passar despercebida, por ser muito natural à criação artística. Em um paradigma de criação colaborativa, porém, ela é fundamental. Acreditamos que encontros periódicos são essenciais para que a colaboração se consolide, pois é durante essa instância que são revistas, testadas e avaliadas praticamente todas as instâncias de decisão anteriores. Essa etapa encontra espelhamento em Reynolds (2002), que, ao descrever o Impetus, conclui que, assim que a composição tenha começado, ele age para guiar, em uma perspectiva bidirecional, a coerência do todo, por meio de uma rede de relações subjetivas, enquanto simultaneamente dirige a integridade do detalhe cumulativo, por uma rede de relações objetivas, a nosso ver, em uma constante reavaliação.

Podemos observar na Fig. 1 um esquema de organização das instâncias de decisão em um processo colaborativo. Fica evidente que tomamos emprestado terminologias e alguns aspectos organizacionais de ambos os teóricos para elaborar nosso esquema. É também necessário salientar, assim como fizeram Reynolds e Laske, que esse não é um esquema fechado. Enquanto algumas instâncias podem ou não aparecer em um processo de colaboração, outras decisões acerca da criação podem ser tomadas unilateralmente, assim como pode não haver uma etapa de planejamento tão intensa e definitiva, passando apenas de algumas ideias básicas à implementação em si. Cada processo é único e pode seguir caminhos muito diversos, com incontáveis variáveis. Nossa proposta com este texto é oferecer uma reflexão o mais abrangente possível sobre prováveis instâncias de decisão dentro de um processo de composição colaborativa. 


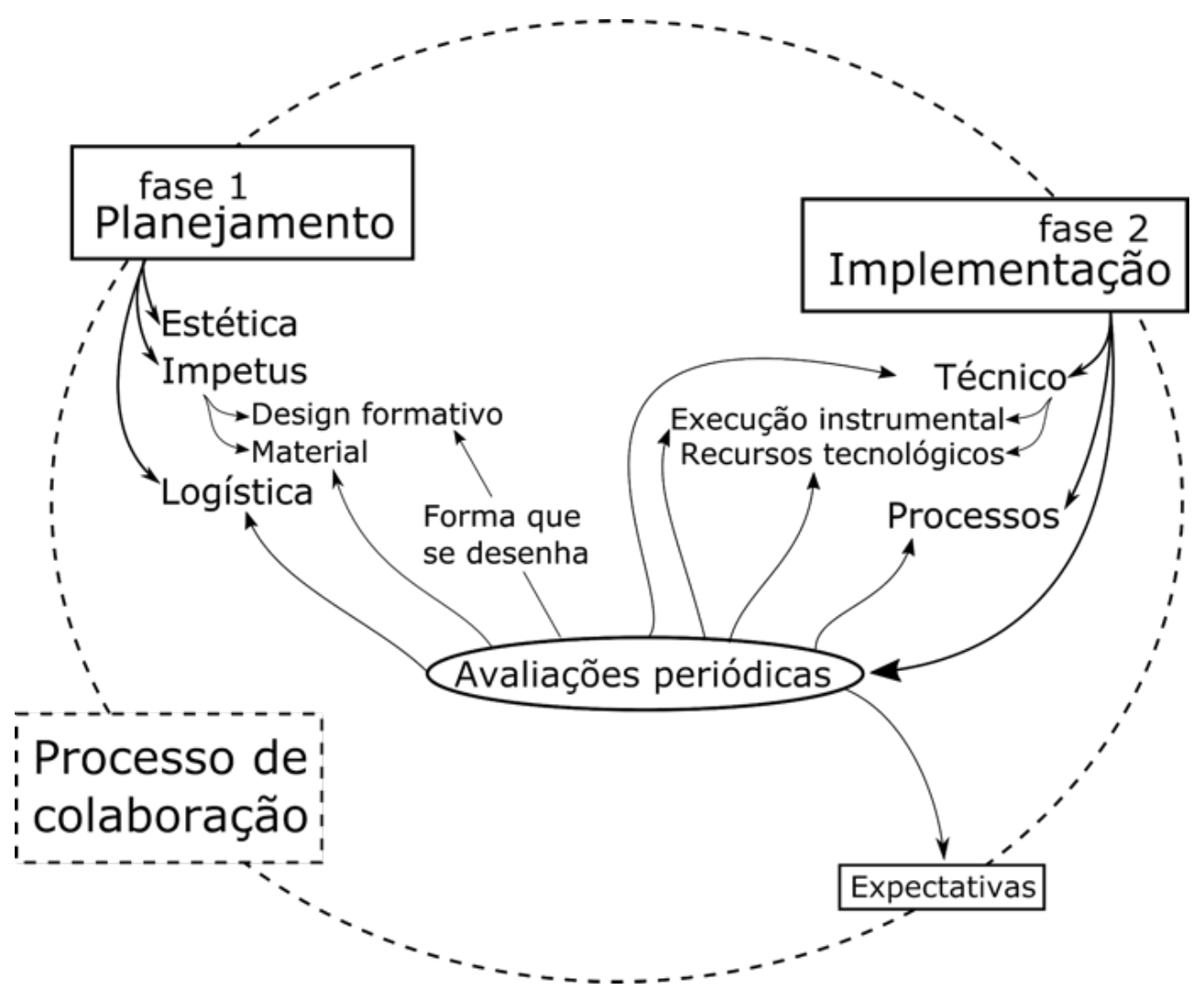

Fig. 1: Esquema das instâncias de decisão compartilhada.

\section{Berimbau: impetus e contextualização}

Os caminhos que desembocam nas ideias que originaram qualquer obra de arte são muitos e quase impossíveis de serem traçados. No caso desta colaboração, por conta talvez dos longos diálogos realizados de maneira informal no início do trabalho e da intenção de fazer um registro do processo, as memórias nos são muito nítidas. É bem claro, por exemplo, como surgiu a ideia germinativa da obra. Conversávamos sobre interesses individuais em busca de algum cruzamento entre eles que pudesse fazer sentido.

O compositor falou dos seus interesses em utilizar aspectos culturais da Bahia como "parte de um jogo dialético e criativo que perpassa o pensamento composicional dos compositores da Bahia" (RIOS FILHO, 2010, p.36) e questionou a performer sobre suas relações com esses objetos culturais ou se havia algo em particular que chamasse a atenção dela com relação à Bahia. Nesse momento, surgiu o nome de um determinado álbum de Gilberto Gil que ambos gostamos muito. Ao ouvir a primeira música do álbum, "Parabolicamará", a "iluminação" foi imediata. Berimbau! Retrospectivamente falando, foi nesse momento que compartilhamos a decisão sobre uma das instâncias mais definidoras do trabalho artístico: o impetus.

Ao escolher o berimbau como impetus para nossa colaboração, explicitamos nosso interesse pela cultura baiana. O berimbau é um instrumento muito popular na Bahia. Não é à toa que pode ser comprado em qualquer loja de souvenirs nos pontos turísticos de Salvador. Sendo culturalmente tão importante, está associado a um grande back- 
ground cultural que contém não somente seus sons, mas toda uma rede de relações que se forma a partir dele.

Instrumentos musicais têm grande significado para a identidade e singularidade de práticas musicais tradicionais. Como um produto de cultura e também como ferramenta para articular sentido cultural, um instrumento se torna um lugar privilegiado para reter essa memória e pode levar consigo uma considerável bagagem cultural para novos contextos. Ao evocar e simbolizar uma construção de espaço, instrumentos se tornam pivô nas narrativas identitárias, como apontam Neuenfeldt (1998) e Jähnichen (2013).

De fato, a obra Berimbau é toda articulada a partir do background cultural que o instrumento carrega consigo. Isso se dá, no entanto, não a partir de um material musical específico, mas do instrumento em si. A partir desse impetus, ainda na fase do planejamento, surgiram as primeiras definições na instância dos materiais. Outras decisões sobre materiais aconteceram posteriormente, ainda a partir do impetus, mas já na instância das avaliações periódicas. Desdobraremos alguns desses episódios adiante.

Considerando o exposto, utilizamos como material composicional, de maneira geral: 1) alguns padrões rítmicos tradicionais da capoeira, prática cultural à que o berimbau está intimamente associado e da qual é o principal instrumento. "Quem manda na roda é o berimbau" é dito por todo mestre em toda aula de capoeira. Esses padrões são usados tanto literalmente quanto desconstruídos, seja nas partes do piano, da voz, seja na eletroacústica; 2) trechos de cantigas associadas à capoeira também são utilizados, tanto na parte eletroacústica quanto ao vivo pela pianista; 3) trechos de uma gravação de Mestre João Pequeno, ícone da capoeira angola, são utilizados na parte eletroacústica; 4) a definição de capoeira do Mestre Pastinha ${ }^{6}$, outro ícone da capoeira angola, é dita pela pianista na parte central da obra; 5) o piano é preparado com partes do berimbau na performance ao vivo, e sons dessa interação, das partes do berimbau com a parte interna do piano, também são utilizados na parte eletroacústica.

Os materiais empregados foram de extrema importância para a definição do design formativo, contribuindo sobremaneira para delinear as seções e a narrativa da obra. De maneira sucinta, vamos agora descrever o design formativo da peça e, mais especificamente, os materiais utilizados em cada uma de suas partes. Essa descrição pode ser importante também para situar o leitor quando surgirem referências sobre esses materiais nas discussões sobre os episódios do processo colaborativo.

A obra tem basicamente três partes, as quais, depois de apresentadas, retornam sempre transformadas. Na parte A, denominada "Angola", o material utilizado é o padrão rítmico tradicional da capoeira de mesmo nome, que é aqui desconstruído. Essa parte tem duração, na sua primeira vez, de 1 minuto e 20 segundos, sendo condensada posteriormente a cerca de 40 segundos.

Denominada "Cavalaria", a parte B utiliza como condutor o padrão de mesmo nome, que se ouve, tocado por um berimbau, na parte eletroacústica. No piano, aparecem três materiais, dois cordais e um arpejado, além das palmas características da capoeira e da voz, que apresenta uma onomatopeia do som do berimbau (wah-wah) 
e o grito de lê, também característico da capoeira. Essa parte retorna mais duas vezes, cada vez mais extensas. A terceira vez inclui um novo gesto utilizando voz e piano, que será descrito nos episódios.

A parte $C$, denominada "Berra-boi", faz um overlapping com a parte B e é de caráter improvisativo. Essa parte tem como materiais uma cantiga tradicional de capoeira, que aparece na eletrônica e na voz da performer, e a definição de capoeira apresentada por Mestre Pastinha, além de materiais oriundos das partes anteriores. A forma geral, portanto, fica como descrita na Tab. 1.

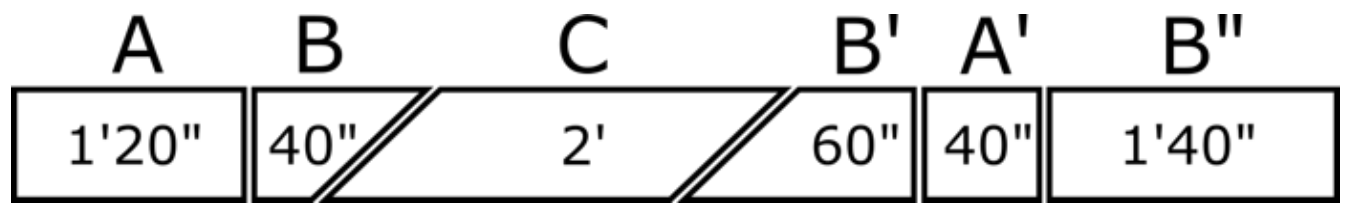

Tab. 1: Seções de Berimbau incluindo seu tempo cronométrico.

Ainda sobre o impetus e os materiais utilizados na obra, um processo importante foi o de tentar simular os sons característicos do berimbau no piano. Os desafios técnicos que surgiram, a nosso ver, conferem singularidade a essa obra. $O$ berimbau consiste em uma corda de aço esticada em uma vara (beriba), amplificado por uma cabaça utilizada como caixa acústica. A corda é percutida com uma vareta. Com uma pedra ou dobrão, ao encostar na corda, o tocador modifica o som do instrumento 7 .

Além do som da corda solta e da corda totalmente presa pelo dobrão, outros dois sons muito característicos nos chamam a atenção: 1) o do dobrão parcialmente preso, causando um chiado na corda; e 2) o de wah-wah produzido ao encostar e afastar a cabaça do instrumento na barriga do tocador. Ambos são recursos importantes, tanto técnica quanto esteticamente, para a execução do instrumento. Emular esses dois sons, tão essenciais do universo do berimbau, no piano, mostrou-se um desafio instigante.

O chiado da pedra foi solucionado de maneira bem simples: o piano foi preparado posicionando dois dobrões sobre as cordas agudas da sua harpa, funcionando basicamente da mesma maneira como funciona no berimbau. $O$ som de wah-wah, por sua vez, foi emulado pela eletrônica: o piano ataca simultaneamente notas específicas junto com o tape, que contém um som gerado por síntese que simula o som do berimbau ao ser encostado na barriga.

Durante nossas sessões de experimentação com partes do berimbau dentro da caixa acústica do piano, um paralelo entre as cordas do piano e a corda do berimbau começou a ser delineado em nossa colaboração. Com o passar do tempo, esse paralelo assumiu tamanha força que passamos a pensar no piano, metaforicamente, como um superberimbau: o berimbau é uma corda estendida, percutida com uma baqueta e amplificada por uma caixa acústica, como já mencionado. O piano, por sua vez, nada mais é que várias cordas estendidas, percutidas por um mecanismo complexo e amplificado por uma grande caixa acústica. 


\section{Episódios no processo de colaboração}

Seria impossivel discorrer sobre todas as decisões tomadas durante qualquer processo criativo, seja colaborativo ou não. Entretanto, através da investigação dos documentos do processo, podemos observar momentos específicos, nos quais a interação compositor-performer foi decisiva para o resultado. Alguns desses momentos - que estamos chamando de episódios - serão apresentados a seguir. Para tanto, faremos uso, além de nossas memórias, de recursos como trocas de mensagem de texto e voz pelo WhatsApp, e-mails e diversas versões da partitura que indicam os caminhos da evolução da obra e a cronologia da colaboração. Infelizmente, não existem versões da parte eletroacústica.

Temos oito versões da partitura, além da que consideramos final. Por meio delas, pode-se perceber a importância das avaliações periódicas em um processo de colaboração com encontros regulares. Na primeira versão, temos apenas a parte A. No encontro em que trabalhamos com essa versão da partitura, não houve alteração no material escrito. $O$ trabalho todo consistiu em evidenciar as deixas da eletrônica, pois essa parte tem alguns pontos que necessitam de perfeita sincronia. A segunda versão já tem as partes $A$ e $B$ completas, enquanto a terceira, além dessas, traz um esboço da parte $C$. Já a quarta versão traz o gesto arpejado de $B$ (episódio 1) já na forma definitiva, mas, nessa versão, a parte $C$ ainda aparece apenas esboçada (de fato, ela só aparece completa na oitava versão).

Na quinta versão, temos o que poderíamos chamar de estrutura completa da obra. Vale apontar, entretanto, que tivemos quatro novas versões posteriores a essa, as quais até poderíamos considerar que a obra estivesse "concluída". Isso mostra quanto trabalho de colaboração aconteceu na fase das avaliações periódicas. Nesta versão, a quinta, percebemos que tanto o novo gesto que aparece em B" quanto o final da obra não "convenciam" nem à performer nem ao compositor (episódio 4).

Na sexta versão, temos a inclusão das palmas e da voz (episódio 2), uma outra sugestão de final e um gesto totalmente novo em B". Trabalhamos também com o final e as deixas de eletrônica para sua sincronia e no novo gesto de B" (episódio 3). Começamos então a discutir sobre a necessidade de um click-track (episódio 4) e a possibilidade de uma seção apenas com palmas e voz no meio de B".

Na sétima versão, temos o novo gesto de B" e a seção com apenas palmas e voz, que, durante o encontro de trabalho, percebemos curta. Além disso, a performer sinalizou que havia muitas trocas de página, então mudamos a orientação da partitura (de paisagem para retrato) e fizemos pequenas mudanças no layout a fim de diminuir a quantidade e assim facilitar as viradas de página. Na oitava versão, essas decisões já estão incorporadas e a parte $C$ aparece pela primeira vez em sua versão definitiva. Da oitava versão para a final, foram incluídas as marcas de tempo de sincronização com a parte eletroacústica e uma pequena improvisação que a performer fazia em um gesto de $A^{\prime}$, que o compositor optou por incorporar à partitura.

Mais uma vez, é importante salientar os efeitos transformadores de alguns desses episódios, que reforçam o caráter distribuído da criatividade. Durante nossos workshops, 
íamos, pouco a pouco, experimentando ao piano todos os materiais escritos pelo compositor. Isso nos proporcionou uma contínua, quase microscópica, avaliação de questões técnicas e de performabilidade, com a participação ativa da performer tanto na definição dos materiais acústicos quanto na escolha de guias de sincronização com a parte eletroacústica. Abordaremos a seguir quatro exemplos práticos desses episódios em Berimbau.

\subsection{Experimentação no primeiro gesto ${ }^{8}$ de arpejos}

Estávamos na fase de implementação da obra. De fato, já era a segunda versão da partitura quando o compositor surgiu com os primeiros gestos musicais específicos da seção B. A ideia era criar, além do material cordal, métrico, sincronizado com o ritmo do berimbau na eletroacústica, uma estrutura mais fluida, com relativa liberdade rítmica, contrastante com a primeira. A lógica de estruturação do gesto, no planejamento do compositor, parecia funcionar perfeitamente. Entretanto, do ponto de vista da performance, a organização das notas trazia uma dificuldade de execução que foi imediatamente ressaltada pela pianista. A escrita lhe parecia comprometer o caráter fluido desse material, que deveria ser mais confortável para poder chegar à fluidez e ao andamento almejados.

Completamente construído com versões da classe de conjuntos 4-17 (0347) material formava um cromatismo perfeito, mas, separado por uma oitava, manteria a sonoridade do conjunto em questão. Esse gesto, em sua primeira tentativa (Fig. 2), estava organizado com as notas cromáticas de duas a duas, o que se mostrou pouco pianístico. Talvez pela formação do compositor, percussionista popular, imaginar um gesto que se assemelhasse a paradiddles ${ }^{10}$ pudesse parecer simples, mas, tecnicamente ao piano, revelou-se um desafio que talvez não valesse o esforço.

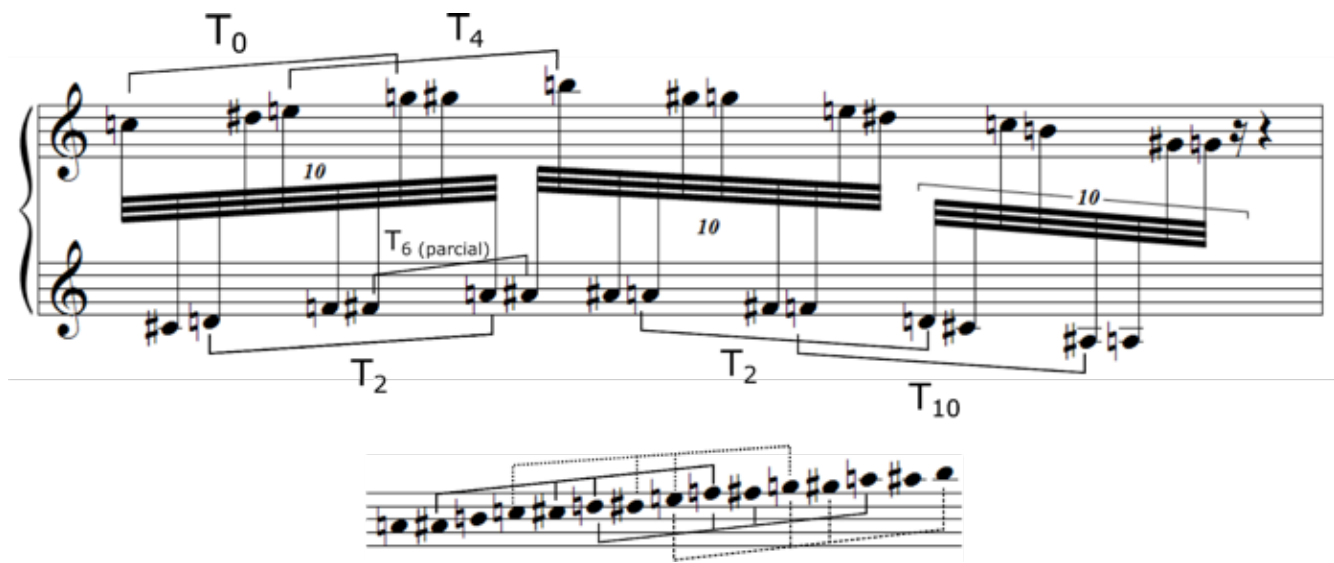

Fig. 2: Gesto em arpejos da seção B como concebido inicialmente, evidenciando sua estruturação complexa por conjuntos de classes de notas.

8 Gesto aqui é entendido, grosso modo, como o movimento de massa sonora no espaço de tessitura (ESPINHEIRA, 2011, p.84). Como metáfora corporal, está associado com a energética e a cognição. Bertissolo (2013, p.26) apresenta uma ampla revisão sobre a noção de gesto.

9 Optamos pela utilização do padrão adotado no livro Introdução à teoria pós-tonal, de Straus. Nessa publicação de referência, as classes de conjuntos são designadas pelo nome de Allen Forte juntamente com sua forma prima entre parênteses e sem vírgulas (STRAUS, 2013, p.61). Uma lista completa das classes de conjuntos pode ser encontrada no apêndice do livro. 
Depois de muito diálogo e experimentação, chegamos a uma solução que, apesar de menos complexa, considerando a construção estrutural com os conjuntos de classes de notas, possibilita fluidez e liberdade rítmica muito maiores. O novo gesto permite a execução em arpejos de quatro ou cinco notas, que podem ser organizados da maneira mais confortável pelo performer, respeitando as individualidades de cada pianista, e certamente possibilitando maior precisão e fluidez, o que era a intenção. Ao mesmo tempo, o contraste com o material cordal da mesma seção se intensifica, já que é menos denso, como se pode ver na Fig. 3.

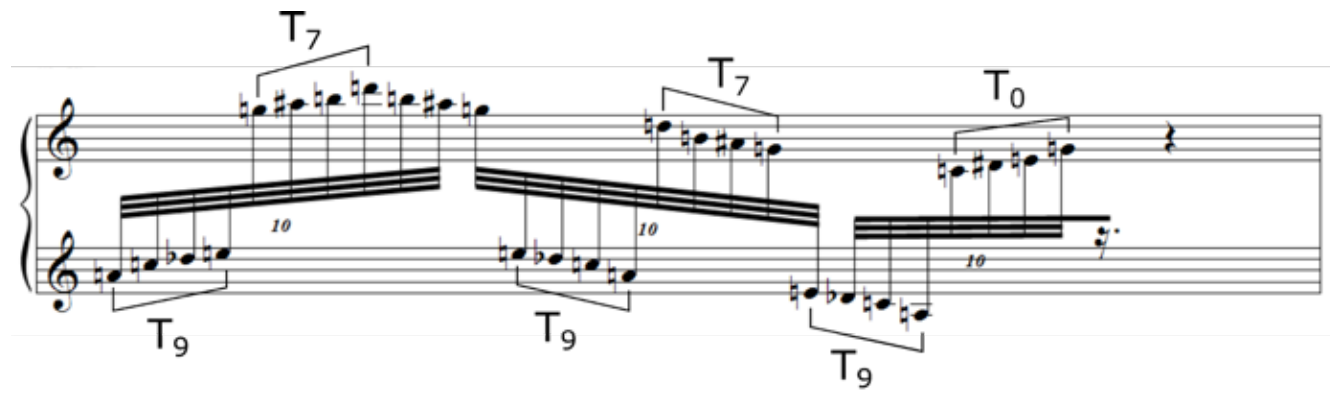

Fig. 3: Gesto em arpejos da parte B depois de trabalhado em colaboração, evidenciando a estruturação mais simples com conjuntos de classes de notas.

A partir desse primeiro episódio, observamos dois aspectos importantes de um processo colaborativo. O primeiro é a necessidade de ambos os colaboradores estarem de espírito aberto no processo. Nota-se que, em certos momentos, é importante ceder em algumas convicções para que a música funcione melhor na performance. $O$ segundo é que determinadas decisões podem não pertencer apenas a uma instância. É evidente que tratamos, nesse episódio, da fase de implementação, na qual são definidos aspectos técnicos de execução instrumental, mas, de certa forma, estávamos trabalhando também na instância em que os materiais são reavaliados, ou seja, na instância das avaliações periódicas.

\subsection{Voz e palmas}

Um elemento que surgiu no decorrer da colaboração, mais precisamente na quinta versão da partitura, foram as palmas. Esse elemento, que assume papel essencial na versão final da obra, nasceu de uma troca de mensagens pelo WhatsApp, enquanto a pianista estudava um trecho recém-escrito pelo compositor. Eles já haviam conversado sobre a necessidade de reforçar o uso da voz na peça, que parecia estar subutilizada. Considerou-se também, caso não chegassem a nada convincente, até mesmo eliminá-la da obra. Foi então que esta troca de mensagens aconteceu:

[...] Alexandre, eu fiquei pensando se não seria interessante incluir, além da voz, palmas... Sei lá... Pensando nesse gesto novo, contrastante com tudo que veio antes... Quem sabe a gente pudesse incluir algo percussivo, e as palmas... enfim, pense aí o que você acha disso. A gente pode experimentar junto. Acho que essa seção nova pede um crescendo e as palmas podem ajudar nisso. (CARDASSI, 26 fev. 2019, 9:39). 
O compositor responde:

[...] a ideia das palmas é interessante. Eu não tinha pensando nisso, não, mas é interessante, porque na capoeira você tem palmas também, né? Eu estava pensando em encaixar algumas coisas de voz nessa parte da cavalaria, um "iê" ou outro, mais espaçado, e poderia talvez encaixar palmas ali também... e coisas tipo a voz imitando o berimbau, o chiado da pedra, o ton, o din, talvez até esvaziar um pouco a eletrônica para encaixar essa voz. Não sei. Era isso que eu estava pensando... E talvez pudesse ter palmas nesse momento também. (ESPINHEIRA, 26 fev. 2019, 9:46).

A conversa continua:

[...] que bom que você gostou da ideia das palmas, Alexandre. [...] Gosto também da ideia de ter mais voz nesse trecho, imitando os sons do berimbau - acho ótimo. Cuidado nesses trechos da cavalaria porque já são gestos bem cheios, e ter mais um elemento, na voz, talvez possa ficar muito complicado de fazer, ou, sei lá, talvez possa facilitar! A gente precisa experimentar... Minha impressão é que esse material novo do piano ainda não chegou onde precisa. Ele pode ficar mais impactante, e talvez uma combinação com a voz no gesto, ou combinação com as palmas, ou... sei lá... tô viajando aqui. (CARDASSI, 26 fev. 2019, 9:50).

O que podemos observar nessa troca de mensagens de voz é que, de maneira informal, foram se delineando possibilidades criativas que resultaram em um dos elementos centrais da peça: a combinação de voz e palmas. A contínua revisão e avaliação dos materiais e gestos, além dos aspectos técnicos, que aconteciam inicialmente durante as sessões de estudo individual da pianista, evidenciam a posição central que as avaliações periódicas assumem durante um processo colaborativo. Esse contínuo experimentar, questionar, sugerir, alterar, reforçar, que levou em nosso caso a muitas versões da peça e da partitura musical, é uma das partes que mais diferenciam o processo criativo colaborativo daquele individual. No caso de Berimbau, o continuum de avaliações se deu de uma forma bastante orgânica e desprovida de formalidades, decorrente talvez da personalidade e da amizade entre os colaboradores.

\subsection{Sincronização}

No início da colaboração - nas instâncias de decisão de planejamento em que discutimos a logística do trabalho -, nossa intenção era que a sincronização entre a parte acústica e a eletrônica da peça fosse feita por meio de guias de sincronização, sem necessidade de uma faixa de click-track. Assim como os "guias de performance" sugeridos por Chaffin e Lisboa (2008), nossos guias de sincronização funcionam como guias de memória, que oferecem, na eletrônica, o conteúdo necessário para que a performer possa se orientar durante a performance.

Assim, a pianista participou ativamente da definição dos guias de sincronização, a fim de que a performance acontecesse de maneira mais expressiva, com relativa liberdade temporal do performer em contraste com a inflexibilidade da faixa de áudio. 
Sabendo que algumas seções no áudio estavam sendo construídas sobre um alicerce rítmico explícito, que incluía vozes dos capoeiristas, parecia, inicialmente, que a sincronização por meio de guias não seria problema.

De fato, as sugestões iniciais de guias de sincronização foram sendo trazidas pelo compositor para experimentação em nossos encontros, e foram poucas as sugestões da pianista: aumento de volume em pontos específicos do áudio, para facilitar a escuta durante a performance, ou breve improvisação ao piano enquanto se esperava determinado guia no áudio. Parecíamos, portanto, estar caminhando para uma sincronização unicamente através de guias de sincronização, sem cronômetro ou click-track - como era nosso objetivo. No entanto, quando chegamos ao final da peça (literalmente nos últimos dois minutos da peça), um enovelamento da textura, com várias linhas de berimbau acontecendo em tempos diferentes no áudio, mostrou-se um empecilho na sincronização. Os gestos ao piano também se intensificavam nesse final, o que impossibilitava a escuta de uma linha de berimbau específica - o nosso guia - dentro da eletrônica.

Em suma, para conseguirmos alcançar o objetivo estético de total alinhamento entre os dois meios, com a certeza de que "chegaríamos juntos" no último gesto da peça, sem hesitação e em total sincronia, optamos por desenvolver uma faixa específica - customizada - de click-track, que nos proporcionaria todos os guias necessários, diretamente no ouvido da pianista. Assim, a faixa de áudio pôde ser manipulada de forma a ressaltar alguns dos guias com os quais a performer deveria interagir, com a inclusão de alguns momentos em que um metrônomo era disparado, mas apenas onde expressamente necessário, funcionando mais como estratégia de checagem e para a segurança da pianista.

Um dos pontos importantes dessa faixa de click-track customizado foi que pudemos incluir também contagem regressiva para entrada de nova seção, depois de trechos menos rítmicos - em que a pianista ficou mais livre para fazer suas escolhas de número de repetições, por exemplo -, o que não faria sentido com um metrônomo ininterrupto. A colaboração na criação dessa faixa de click-track customizado foi, de fato, uma das decisões compartilhadas mais produtivas deste trabalho, através da qual, se não estivéssemos trabalhando conjuntamente, o resultado teria sido absolutamente outro.

\subsection{Experimentação no último gesto}

O último material composto para a peça foi um gesto que é apresentado apenas na última seção e evidencia a importância das avaliações periódicas para o processo criativo. Ele aparece no início da seção B". Alguns fatores contribuem para que, em teoria, o ouvinte já esteja acostumado e talvez até cansado dos materiais musicais da seção:

1. os materiais da seção $B\left(B, B^{\prime}\right.$ e $\left.B^{\prime \prime}\right)$ já foram ouvidos outras duas vezes;

2. todas as vezes em que a seção $B$ se inicia, ouve-se antecipadamente os berimbaus na eletrônica e logo a seguir o primeiro gesto cordal da seção seguido pelo gesto em arpejos;

3. as seções B sofrem alteração de duração ao longo da peça, como se pode observar na Tab. 1; 
4. De B para B', os materiais foram alongados e desenvolvidos, mas as seções se iniciam exatamente iguais.

Depois de já termos experimentado diversas vezes esses materiais, em vários encontros, e sendo a seção B" ainda mais extensa que as anteriores, sentimos a necessidade de renovação dos materiais, para gerar uma condição de surpresa no espectador. Sobre expectativa e surpresa em música, Bertissolo (2016, p.197) comenta:

Os padrões de expectativa e surpresa são articulados em uma complexa rede de relações entre informações prévias e condições realizadas no ato da escuta musical. É a partir da formulação de uma expectativa que se pode surpreender musicalmente. É preciso o estabelecimento de um padrão capaz de projetar o movimento de expectativa. Sem expectativa não há surpresa.

Cabe dizer que, antes desse gesto, experimentamos outra ideia, mas optamos por descartá-la. Como essa fase de avaliações periódicas ocorreu ao mesmo tempo em que discutíamos a sugestão das palmas e a necessidade de intensificação do uso da voz (episódio 2), o compositor passou a buscar um gesto que juntasse todos os recursos acústicos disponíveis. Foi assim que se chegou a esse gesto novo, que inclui a voz e clusters nos registros preparados do piano (Fig. 4).

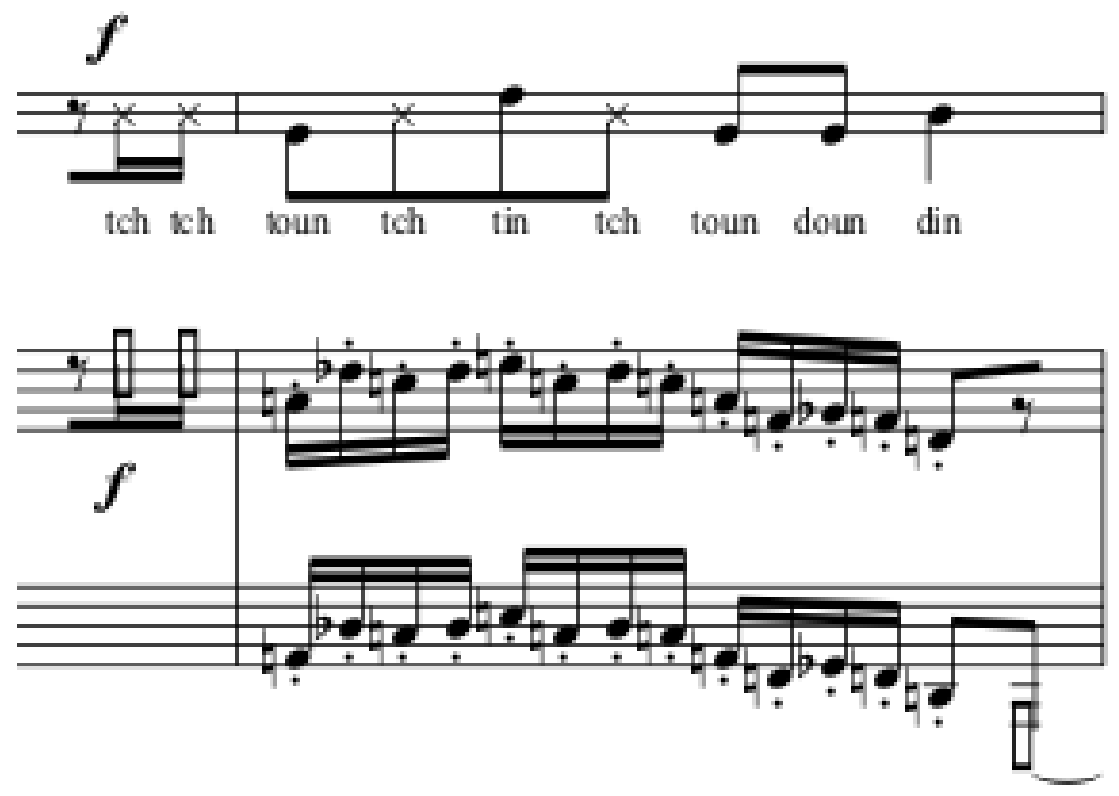

Fig. 4: Primeira versão do gesto novo da seção B".

A primeira versão desse gesto, entretanto, revelou dificuldades técnicas, que pareciam ir de encontro à agilidade e à leveza que buscávamos nele. A quantidade de notas em andamento rápido comprometia a precisão rítmica e a sincronização. Em decorrência do registro e do volume, o piano se sobrepunha à voz em vários momentos. No entanto, após várias tentativas, durante uma sessão de workshop exclusiva para esse 
problema, chegamos à versão que nos pareceu ser a definitiva desse gesto. Nela, uma redução nos clusters e na continuidade das oitavas, e, portanto, da intensidade do gesto como um todo, permite que a voz não seja encoberta pelo piano (Fig. 5).

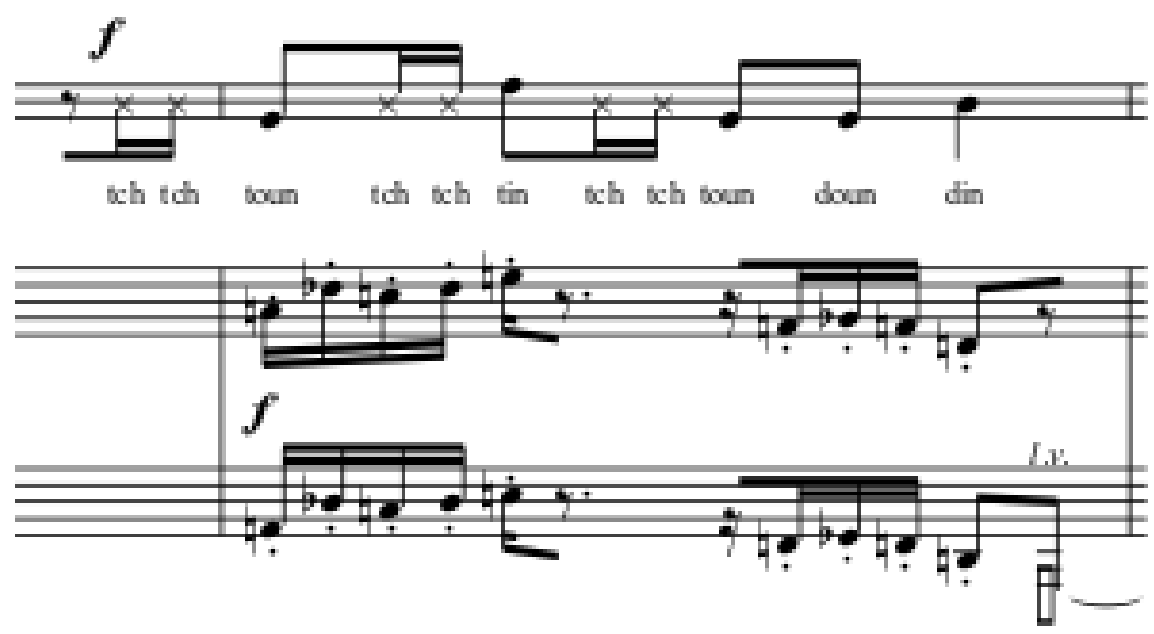

Fig. 5: Versão final do gesto novo da seção B" depois de trabalhado em colaboração.

Enquanto continuávamos com nossas avaliações periódicas, já pensando na peça em sua completude, alguns questionamentos foram levantados, especificamente sobre esse gesto, pois é um elemento que aparece apenas no final da obra e não é desenvolvido. Essa questão, a princípio, incomodava tanto a performer quanto o compositor. Entretanto esse material novo parecia cumprir bem a função de quebra de expectativa daquela seção já tão repetida. Juntamente com uma pequena seção de vinte segundos, em que se esvazia a eletrônica e ficam só as palmas e a voz, esse gesto imbui a parte B" de um ar renovado e contribui, acreditamos, para um final mais convincente. Isso levou os colaboradores a manter o gesto mesmo sem um "esperado" desenvolvimento.

\section{Considerações finais}

Procuramos propor neste artigo um modelo de organização de processos colaborativos em instâncias de decisão compartilhada à luz da bibliografia atual, notadamente aquela sobre colaboração artística, criatividade distribuída e teorias da composição. Essa proposta de organização, que esperamos que seja útil a artistas, colaboradores e pesquisadores interessados em processos criativos, surgiu durante a colaboração que os autores deste texto desenvolveram em 2018-2019 e que resultou na composição de uma obra eletroacústica mista.

Reconhecendo a singularidade de cada processo criativo e tomando nossa colaboração apenas como exemplo ${ }^{11}$, procuramos refletir sobre os efeitos transformadores de algumas experiências que evidenciam o caráter distribuído da criatividade. Chama-

\footnotetext{
11 Em nosso caso, a colaboração se deu entre um compositor e uma performer, mas outros processos colaborativos acontecem com diversos formatos, incluindo compositores que também tocam, performers que também compõem, podendo haver uma infinidade de outras possibilidades, com interações interdisciplinares, inclusive.
} 
mos essas experiências de episódios. Escolhemos quatro episódios de Berimbau para exemplificar como o nosso compartilhar de decisões se deu e como esses episódios - situados dentro de instâncias de decisão compartilhada - impulsionaram nosso processo colaborativo e, decididamente, direcionaram o resultado artístico.

Faz-se necessário aqui uma nota sobre a necessidade de flexibilidade ao se abordar um processo criativo sob o prisma da colaboração. É evidente que nem todas as decisões precisam, necessariamente, ser tomadas conjuntamente. De fato, um modelo de colaboração mais participativo, como o que propomos aqui, tem como princípio o fato de que as ideias sugeridas por um indivíduo são destrinchadas pelos demais colaboradores e de que é por meio de experimentação, questionamentos, adaptação, negociação e desenvolvimento dessas ideias que se chega a uma visão artística compartilhada entre os colaboradores (CARDASSI; BERTISSOLO, 2020). Acreditamos que a descrição de cada episódio neste artigo ilustra a negociação e a chegada a uma visão artística compartilhada por nós, compositor e performer, colaboradores em Berimbau.

Por meio da análise dos quatro episódios, podemos constatar, retrospectivamente, a parceria nas decisões, a participação ativa da performer e a natureza distributiva e de reciprocidade de nossa colaboração. Nenhum de nós buscava o anulamento de nossas áreas de expertise. Mesmo quando as ideias foram trazidas (aparentemente de modo unilateral) pelo compositor, elas foram trabalhadas exaustivamente com a performer em sessões de experimentação que continuaram por toda a fase de implementação, tanto na instância técnica da execução instrumental quanto na instância das avaliações periódicas. Foi esse contínuo trocar de ideias, experiências, acertos e erros que produziu essa responsabilidade compartilhada pelas decisões e pelo resultado da colaboração. Através da reciprocidade em um processo colaborativo, as áreas de expertise dos indivíduos não são anuladas, mas aprofundadas, como bem apontou John-Steiner (2000) ao discorrer sobre o que a autora chama de paradoxo da reciprocidade.

Acreditamos que trabalhos colaborativos de natureza participativa, como o discutido neste artigo, oferecem uma alternativa ao "cenário de suposições que continuam a dar prioridade ao texto sobre a performance, e que celebra a autoanulação do performer ao interpretar aqueles textos" (DOFFMAN; CALVIN, 2017, p.4). Ao deixar de ser apenas um instrumentista em busca de soluções técnicas, o performer que participa ativamente em colaborações mais fluidas escancara sua postura de agente criativo no processo de colaboração. Decorre desse compartilhar de responsabilidades sua sensação de pertencimento e de representatividade no trabalho colaborativo.

Sem a pretensão de sugerir que esse seja um caminho único, nosso modelo visa propor possibilidades de reflexão sobre novos paradigmas de composição colaborativa e sobre sua aplicabilidade para jovens artistas interessados em criações artísticas mais fluidas. Apesar do contínuo interesse por colaborações artísticas na atualidade, parece-nos que ainda há uma lacuna acerca da teorização de como esses processos acontecem. De fato, nossos processos de colaboração têm acontecido de maneira empírica e intuitiva e, mesmo em situações onde a colaboração é bem-vinda, frequentemente não sabemos ao certo como proceder (CARDASSI; BERTISSOLO, 2019, 2020). Isso se dá porque os papéis de compositor e performer são mantidos e reforçados durante os anos de educação formal de ambos. 
Ao refletir sobre instâncias de decisão compartilhada em um processo colaborativo - reconhecendo a carência de alternativas que promovam o entrelaçamento das áreas durante os anos de formação -, procuramos oferecer alternativas para a compreensão e para o estudo de como os processos colaborativos podem ser desenvolvidos. Acreditamos que, muitas vezes, existe o interesse por colaboração entre jovens estudantes compositores e performers, mas que carecem de elementos e de experiência suficientes para saber como organizar, desenvolver e levar a cabo um processo colaborativo. Esperamos que este artigo venha a suprir, mesmo que parcialmente, essa lacuna.

\section{Referências}

BARRETT, Margaret S. Collaborative creative thought and practice in music. SEMPRE Studies in The Psychology of Music. Surrey: Ashgate, 2014.

BERTISSOLO, Guilherme. Composição e Capoeira: dinâmicas do compor entre música e capoeira. Tese (Doutorado) - UFBA, Salvador, 2013.

BERTISSOLO, Guilherme. O pato-coelho da criação em música: intencionalidade, experiência e intersubjetividade. In: LIMA, Paulo Costa (org.). Pesquisa em música e diálogos com produção artística, ensino, memória e sociedade. Vol. 1. Salvador: EDUFBA, 2016. p. 221-236. (Série Paralaxe).

CARDASSI, Luciane. [Sugestão de palmas]. WhatsApp: [Troca de mensagens com Alexandre Espinheira]. 26 fev. 2019. 9:39. 1 mensagem de WhatsApp.

CARDASSI, Luciane. [Voz, palmas, clusters e a combinação desses elementos em um gesto novo na Cavalaria]. WhatsApp: [Troca de mensagens com Alexandre Espinheira]. 26 fev. 2019. 9:50. 1 mensagem de WhatsApp.

CARDASSI, Luciane; BERTISSOLO, Guilherme. Colaboração compositor-performer: uma proposta de metodologia. In: CONGRESSO DA ASSOCIAÇÃO NACIONAL DE PESQUISA E PÓS-GRADUAÇÃO EM MÚSICA, 29., 2019, Pelotas. Anais [...]. Pelotas: UFPel, 2019.

CARDASSI, Luciane; BERTISSOLO, Guilherme. Shared musical creativity: teaching composer-performer collaboration. Vórtex, Curitiba, v. 8, n. 1, 2020. DOI:

10.33871/23179937.2020.8.1.13

CHAFFIN, Roger; LISBOA, Tania. Practicing perfection: how concert soloists prepare for performance. Ictus, Salvador, v. 9, n. 2, 2008.

CHAVES, Celso G. Loureiro. Processo criativo e composição musical: proposta para uma crítica genética em música. In: CONGRESSO INTERNACIONAL DA ASSOCIAÇÃO 
DE PESQUISADORES EM CRÍTICA GENÉTICA, 10., 2012, Porto Alegre. Anais [...]. Porto Alegre: PUCRS, 2012. Disponível em: http://ebooks.pucrs.br/ edipucrs/anais/apcg/ edicao10/Celso.Chaves.pdf. Acesso em: 15 ago. 2019.

CLARKE, Eric; DOFFMAN, Mark. Distributed Creativity: collaboration and improvisation in Contemporary Music. New York: Oxford University Press, 2017.

COOK, Nicholas. Entre o processo e o produto: música e/enquanto performance. Trad. F. Borém. Per Musi, Belo Horizonte, n. 14, p. 5-22, 2006.

DOFFMAN, Mark; CALVIN, Jean-Philippe. Contemporary Music in Action: performercomposer collaboration within the conservatoire. In: CLARKE, Eric; DOFFMAN, Mark. Distributed Creativity: collaboration and improvisation in contemporary music. New York: Oxford University Press, 2017.

DOMENICl, Catarina Leite. It takes two to tango: a prática colaborativa na música contemporânea. Revista do Conservatório de Música da UFPel, Pelotas, n. 6, p. 1-14, 2013.

ESPINHEIRA, Alexandre. A teoria pós-tonal aplicada à composição: um guia de sugestões compositivas. Tese (Doutorado) - UFBA, Salvador, 2011.

ESPINHEIRA, Alexandre. [A voz imitando o berimbau no gesto novo na Cavalaria]. WhatsApp: [Troca de mensagens com Luciane Cardassi]. 26 fev. 2019. 9:46. 1 mensagem de WhatsApp.

FORTIN, Sylvie. Contribuições possíveis da etnografia e da autoetnografia para a pesquisa na prática artística. Trad. Helena Mello. Cena, Porto Alegre, n. 7, p. 77-88, 2009.

FRUNGILLO, Mário D. Dicionário de percussão. São Paulo: Ed. Unesp, Imprensa Oficial do Estado, 2003.

HAYDEN, Sam; WINDSOR, Luke. Collaboration and the composer: case studies from the end of the 20th century. Tempo, Cambridge, v. 61, n. 240, p. 28-39, 2007.

JÄHNICHEN, Gisa. Field note: musical instruments used in rituals of the Alak in Laos. Asian Ethnology, v. 72, n. 1, p. 119-142, 2013.

JOHN-STEINER, Vera. Creative Collaboration. New York: Oxford University Press, 2000. 
LASKE, Otto. Toward an epistemology of composition. Interface-Journal of New Music Research, n. 20 (3-4), p. 235-269, 1991.

NEUENFELDT, Karl. Notes on Old Instruments in New Contexts. The World of Music, v. 40, n. 2, p. 5-8, 1998.

PAREYSON, Luigi. Os problemas da estética. Trad. Maria Helena Nery Garcez. São Paulo: Martins Fontes, 2005.

REYNOLDS, Roger. Form and method: composing music. New York, London:

Routledge, 2002.

RIOS FILHO, Paulo. Hibridação cultural como horizonte metodológico para a criação de música contemporânea. Dissertação (Mestrado) - UFBA, Salvador, 2010.

RIOS FILHO, Paulo. Um compor emaranhado: composição, teoria e análise ao longo de linhas. Tese (Doutorado) - UFBA, Salvador, 2015.

SALLES, Cecilia A. Crítica genética: uma (nova) introdução. 2. ed. São Paulo: Educ, 2000.

SALLES, Cecilia A. Gesto inacabado: processo de criação artística. 5. ed. ver. e ampl. São Paulo: Annablume, 2014.

STRAUS, Joseph N. Introdução à Teoria Pós-tonal. Trad. Ricardo Mazzini Bordini. Salvador: UNESP/EDUFBA, 2013. 
